\title{
Abordagem de Questões Sócio-Científicas Controversas no 1o Ciclo do Ensino Básico
}

\author{
Fábio Ribeiro \\ Universidade de Aveiro, Portugal. \\ fabioribeiro@ua.pt \\ Celina Tenreiro Vieira \\ Universidade de Aveiro, Portugal. \\ cvieira@ua.pt
}

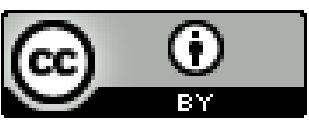

Educação: teoria e prática, Rio Claro, SP, Brasil - elSSN: 1981-8106

Está licenciada sob Licença Creative Common

\section{Resumo}

Assumindo a importância da educação em ciências, desde os primeiros anos, visando a formação de cidadãos capazes de pensar e agir criticamente em situações de cariz científico-tecnológico, realizou-se um estudo com a finalidade de desenvolver situações de aprendizagem focadas em questões sócio-científicas controversas para promover a construção/mobilização de conhecimento científico e capacidades de argumentação dos alunos. O estudo enquadra-se numa metodologia qualitativa, seguindo um plano de investigação-ação. Foi realizado com uma turma do 30 ano (8 anos), tendo sido abordadas questões sócio-científicas controversas, enquadradas em temas curriculares de ciências, recorrendo a estratégias de debate, role-play e escrita de ensaios argumentativos. Na recolha de dados usou-se um instrumento de análise das produções, orais e escritas, dos alunos. $\mathrm{Na}$ análise de dados, privilegiou-se a análise de conteúdo. Os resultados obtidos sugerem que os alunos mobilizaram conhecimentos científicos, evidenciando melhoria no uso eficaz de capacidades de argumentação em foco. Tal permite concluir que a abordagem de questões sócio científicas controversas contribui para a promoção da capacidade de argumentação, bem como para a contrução/mobilização de conhecimentos científicos dos alunos.

Palavras-chave: Educação em Ciências. Questões sócio-científicas. Argumentação.

\section{Socio-Scientific Controversial Issues in 1st Cycle of Basic Education}

\footnotetext{
Abstract

Assuming the importance of science education, from early years, aiming to educate citizens capable of thinking critically and act in scientific and technological contexts, a
} 
study was carried out in order to develop learning situations focused on controversial socio-scientific issues to promote students' argumentation skills and scientific knowledge building / mobilization. The study was based on a qualitative methodology, following an action research plan. It was conducted with a class of 3th grade, having been addressed controversial socio-scientific issues, framed in science curriculum topics, using strategies of debate, role-play and argumentative essays. Data was collected using an analyzing instrument of student's oral and written productions. In data analysis the privileged technique was content analysis. The results suggest that students mobilized requested scientific knowledge, showing improvement in the effective use of argumentation skills required. This allows us to conclude that the approach of controversial socio-scientific issues contributes to the promotion students' argumentation skills as well as for scientific knowledge construction / mobilization.

Keywords: Science Education. Socio-scientific issues. Argumentation.

\section{Abordaje de Cuestiones SocioCientíficas Controversiales en el 10 Ciclo de la Enseñanza Básica}

\section{Resumen}

Asumiendo la importancia de la educación en ciencias, desde los primeros años, y teniendo como objetivo la formación de ciudadanos capaces de pensar y actuar críticamente en situaciones de cariz científicotecnológico, se realizó un estudio con el fin de desenvolver situaciones de aprendizaje centradas en cuestiones sociocientíficas controversiales para promover la construcción/movilización de conocimiento científico y las capacidades de argumentación de los alumnos. El estudio se encuadra en una metodología cualitativa, siguiendo un plan de investigación-acción. Se realizó con un grupo del 3ำ año (8 años), con el que se habían abordado cuestiones sociocientíficas controversiales, encuadradas en temas curriculares de ciencias, recurriendo a estrategias de debate, juegos de rol y escritura de ensayos argumentativos. En la recolección de datos se usó un instrumento de análisis de las producciones, orales y escritas, de los alumnos. En el análisis de datos, se privilegió el análisis de contenido. Los resultados obtenidos sugieren que los alumnos movilizaron conocimientos científicos, evidenciando mejoría en el uso eficaz de las capacidades de argumentación en foco. Tal resultado permite concluir que el abordaje de cuestiones sociocientíficas controversiales contribuye para la promoción de la capacidad de argumentación, así como para la construcción/movilización de conocimientos científicos de los alumnos.

Palabras clave: Educación en Ciencias; Cuestiones socio-científicas; Argumentación.

\section{Introdução}

Atualmente, vivemos numa sociedade fortemente marcada pelos avanços da Ciência e da Tecnologia, o que se reflete e repercute em múltiplos domínios, de que 
são exemplos o desenvolvimento das (inter)comunicações, o controlo e mesmo irradicação de certas doenças e o aumento da esperança de vida dos cidadãos (PEREIRA, 2007). Tais avanços têm contribuído, de um modo geral, para melhoria da qualidade de vida das pessoas.

Todavia, a rápida evolução científico-tecnológica não se tem traduzido apenas em aspetos positivos. A título ilustrativo, a evolução da Ciência e da Tecnologia também tornou possível o desenvolvimento de armas de destruição maciça, como é o caso da bomba atómica (VIEIRA; TENREIRO-VIEIRA; MARTINS, 2011).

Neste quadro, exige-se uma população capaz de se envolver ativamente na sociedade, nomeadamente, na tomada de decisões e posições sobre questões relacionadas com a Ciência e com a Tecnologia. Nesse sentido, é imperioso preparar as crianças e os jovens para, enquanto cidadãos, serem capazes de se envolver e compreender assuntos, questões e problemas com uma componente científica que emergem em contexto social e que afetam a sociedade. Como sublinham diversos autores, em "sociedades democráticas o objetivo primordial do ensino das ciências deverá ser ajudar a preparar cidadãos informados, capazes de refletir, decidir e agir relativamente a assuntos científicos controversos com impacto social" (HILÁRIO; REIS, 2011, p. 87).

Decorrente da importância de formar cidadãos cientificamente capazes de compreender e intervir numa sociedade democrática, a escola deve proporcionar o desenvolvimento de saberes basilares, de maneira a formar cidadãos capazes de se integrarem na sociedade atual, com vista a almejar a tão desejada literacia científica alargada a toda a população. De um modo mais específico, a escola em geral, e a educação em ciências, em particular, devem proporcionar saberes que integrem conhecimentos científicos e capacidades de pensamento, tidos como essenciais ao envolvimento na resolução de questões que a Ciência e a Tecnologia colocam à sociedade e a cada um individualmente.

Segundo Capecchi e Carvalho (2000) e Driver, Newton e Osborne (2000), o desenvolvimento da capacidade de argumentação afigura-se como fundamental, por exemplo, para a compreensão de diferentes visões científicas sobre uma mesma questão. Assim, a abordagem de questões sócio-científicas (controversas), em sala de aula, potencia situações que resultam na escolha entre diferentes pontos de vista, 
evidenciando, assim, a importância da argumentação, na medida em que permite, entre outros aspetos, auxiliar no processo de tomada de decisão (CAPECCHI; CARVALHO, 2000).

Assumindo a importância da educação em ciências - promotora da construção de conhecimentos científicos e do desenvolvimento de capacidades de pensamento, em particular de argumentação, na formação das crianças e jovens para que possam intervir ativa e racionalmente nas diferentes esferas da sociedade - urge desenvolver práticas pedagógica-didáticas coerentes com tal desiderato. Nesse sentido, é fundamental desenvolver estudos que apontem, fundamentadamente, vias de atuação para desenvolver práticas promotoras das capacidades de argumentação dos alunos e da construção e mobilização de conhecimento científico útil e utilizável em diferentes situações e contextos.

Neste enquadramento, realizou-se um estudo com a finalidade de desenvolver (conceber, produzir, implementar e avaliar) situações de aprendizagem focadas em questões sócio-científicas (controversas) para promover capacidades de argumentação e a construção/mobilização de conhecimento científico de alunos do 1 o ciclo do ensino básico (6-9 anos).

Decorrente da finalidade, formularam-se as seguintes questões de investigação: (i) Quais os contributos da abordagem de questões sócio-científicas controversas na promoção de capacidades de argumentação? e (ii) Quais os contributos da abordagem de questões sócio-científicas controversas para promover a construção/mobilização de conhecimentos científicos?

\section{Referencial Teórico}

O ritmo a que a Ciência e a Tecnologia evoluem e se propagam torna difícil o acompanhamento dessas áreas. Apesar disso, todo o cidadão deve manter-se atualizado, acompanhar assuntos de natureza científico-tecnológica, para que possa compreender os problemas do mundo e participar ativamente numa sociedade democrática, evitando que sejam apenas especialistas a tomar decisões sobre questões científicas (REIS, 2009). É da capacidade de participar ativamente em discussões a propósito desse tipo de questões que depende a avaliação pública da 
ciência (REIS, 2004; VIEIRA; TENREIRO-VIEIRA; MARTINS, 2011). Nesta perspetiva, importa que a educação em ciências, desde os primeiros anos, envolva os alunos na abordagem de questões sócio- científicas controversas, promovendo a construção/mobilização de conhecimentos científicos e o desenvolvimento de capacidades de argumentação.

Diferentes autores têm procurado circunscrever o significado de expressões como problemáticas, assuntos ou questões sócio-científicas controversas delineado, bem como delinear quadros de referência sobre a argumentação e as capacidades de argumentação.

Segundo Stiefel et al. (2004), a expressão sócio-científico é comumente associada a temáticas ou questões que emergem do corpo da ciência e que são acompanhadas por uma forte reação ou repercussão social, configurando o termo controversa uma qualidade que acompanha muitos dos acontecimentos que marcam o dia-a-dia da atualidade científica. Analogamente, Reis (2004) e Hilário e Reis (2009) consideram que, a expressão controvérsias sócio-científicas reporta a problemas ou questões que surjam na sociedade, por vezes de forma controversa, e que têm uma componente científica e tecnológica. Já Martins (2011) usa o termo societais para referir temas que envolvem a ciências e de relevância social. Com frequência tais temas, assuntos ou questões societais configuram-se como controvérsias, porquanto há boas razões a favor e contra os diferentes pontos de vistas que, a propósito dos mesmos, podem ser defendidos. Nesse contexto, uma tomada de decisão ou posição sobre uma questão controversa é, muitas vezes, mediada e influenciada por valores, incluindo valores sociais, políticos e económicos

Decorrente disso, diversos autores defendem que a exploração de questões sócio- controversas, em sala de aula, pode ajudar os alunos a desenvolverem uma compreensão mais aprofundada da natureza da ciência e da sua inter-relação com a tecnologia e com a sociedade. Pode, também, possibilitar a focagem de diversos pontos de vista, o que os ajuda a reconhecer que a ciência não é objetiva, livre de valores ou de influência, e a desenvolver atitudes positivas relativamente a uma controvérsia sócio-científica. Pode, ainda, contribuir para a apropriação de conhecimento científico inerente à questão, bem como para o desenvolvimento de capacidades de pensamento, designadamente de pensamento crítico, tomada de 
decisão, comunicação e argumentação (BOCANEGRA; SILVA, 2009; CID et al., 2004; HILÁRIO; REIS, 2009; TENREIRO-VIEIRA; VIEIRA, 2004).

$\mathrm{Na}$ mesma linha, Osborne (2007) afirma que na abordagem de assuntos, problemas ou questões sócio-científicas controversas é crucial a capacidade de argumentação. Para o autor, a argumentação pode ser perspetivada como uma atividade intelectual centrada no apresentar uma posição, sobre uma questão ou assunto, e defendê-la ou justificá-la com base em razões que se pretendem alicerçadas em evidência. A argumentação pode, também, envolver o refutar de uma opinião ou posição, mediante a construção de contra-argumentos que remetem para oposição, esclarecendo e desocultando alternativas de entendimento acerca do assunto ou questão em apreço (BRITO; SÁ, 2010).

A esse respeito, autores como Hakyolu e Ogan-Bkiroglu (2011) e Leitão (2007) salientam que a argumentação assenta em três elementos-base: argumento, contraargumento e resposta. Um argumento envolve duas partes, sendo uma delas a tese e a outra as razões. A tese corresponde ao explicitar da posição que se defende, sendo as razões o elemento que lhe dá suporte, configurando a justificativa (ENNIS, 1996). De um modo mais Zohart e Nemet (2002) afirmam que um argumento pode consistir tanto em asserções como conclusões e as respetivas justificações, suportes ou razões. O contra-argumento encerra a possibilidade de objeção ou oposição podendo desencadear a diminuição de probabilidade de aceitação de um ponto de vista. A resposta, enquanto elemento constituinte da argumentação, corresponde ao considerar e reagir a objeções, decorrente da avaliação da sustentabilidade de argumentos apresentados por um indivíduo ao contra-argumentar.

Nesta perspetiva, a argumentação envolve capacidades, tais como: analisar informação obtida a partir de diferentes fontes de informações; avaliar a credibilidade de fontes de informação; relacionar dados e conclusões; avaliar afirmações, hipóteses ou conclusões com base na evidência disponível; apresentar e defender uma posição, usando linguagem científica adequada e analisar e avaliar razões apresentadas a favor de diferentes pontos de vista, comparando as razões que conferem confiabilidade a cada uma das alternativas (NORRIS; PHILLIPS; OSBORNE, 2007; COSTA, 2008). Envolve, também persuasão, isto é o convencer uma audiência a apoiar um determinado ponto de vista (JIMÉNEZ; ERDURAN, 2008). 
Considerando-se as premissas expostas, diferentes investigações evidenciam a importância do desenvolvimento da capacidade de argumentação dos alunos a propósito de questões societais controversas (CAPECCHI; CARVALHO, 2000; MORTIMER; SCOTT, 2002). Então, é fundamental que o aluno compreenda as diferentes visões que a ciência apresenta sobre uma mesma questão, pois nem sempre os cientistas estão de acordo quando analisam questões sócio-científicas como, por exemplo, o uso de energia nuclear. Assim, importa que o aluno reconheça que a defesa de uma dada posição depende dos diferentes argumentos apresentados, baseados em evidências científicas e em informação factual.

\section{Descrição do estudo}

Decorrente da finalidade da pesquisa, o estudo realizado é de natureza qualitativa, seguindo um plano de investigação-ação, caracterizado por um ciclo de planificação, ação, observação e reflexão, com ciclos sucessivos de avaliação e reflexão associados a etapas de implementação de atividades. Assim, no que reporta à planificação pretendeu-se desenvolver situações de aprendizagem focadas em questões sóciocientíficas controversas e explicitamente orientadas para promover de capacidades de argumentação. Por forma a garantir o apelo a capacidades de argumentação, as situações de aprendizagem foram delineadas com base num quadro de referência construído para o efeito, emergente da revisão de literatura efetuada. Incluiu-se, de seguida, esse quadro de referência (Quadro 1).

\begin{tabular}{|c|c|c|}
\hline \multicolumn{2}{|c|}{ Capacidades de argumentação } & $\begin{array}{c}\text { Capacidades transversais à } \\
\text { argumentacão }\end{array}$ \\
\hline $\begin{array}{l}\text { A - Analisar fontes de } \\
\text { informação credíveis e } \\
\text { relevantes em função de uma } \\
\text { dada questão sócio-científica } \\
\text { controversa }\end{array}$ & $\begin{array}{l}\text { A1 - Identifica razões } \\
\text { A1.1 - A favor de um } \\
\text { determinado ponto de vista } \\
\text { A1.2 - Contra um } \\
\text { determinado ponto de vista } \\
\text { A2 - Compara e pesa razões a } \\
\text { favor e contra um determinado } \\
\text { ponto de vista }\end{array}$ & $\begin{array}{l}\text { D1 - Persuadir/ } \\
\text { Convencer os colegas a } \\
\text { defender a sua posição sobre } \\
\text { uma determinada questão } \\
\text { sócio-científica controversa } \\
\text { D2 - Usar linguagem adequada } \\
\text { incluindo linguagem científica }\end{array}$ \\
\hline $\begin{array}{l}\text { B - Tomar uma posição quando } \\
\text { confrontado com uma questão } \\
\text { sócio-científica controversa }\end{array}$ & $\begin{array}{l}\text { B1 - Apresenta a tese que } \\
\text { defende } \\
\text { B2 - Apresenta razões para } \\
\text { justificar a tese } \\
\text { B2.1 - baseadas em } \\
\text { evidência científica } \\
\text { B2.2 - consistentes com } \\
\text { factos conhecidos } \\
\text { B2.3 - consistentes com a }\end{array}$ & $\begin{array}{l}\text { D3 - Usar linguagem com } \\
\text { correção científica } \\
\text { D4 - Ter em atenção a } \\
\text { audiência (ajustar a linguagem } \\
\text { ao público) }\end{array}$ \\
\hline
\end{tabular}




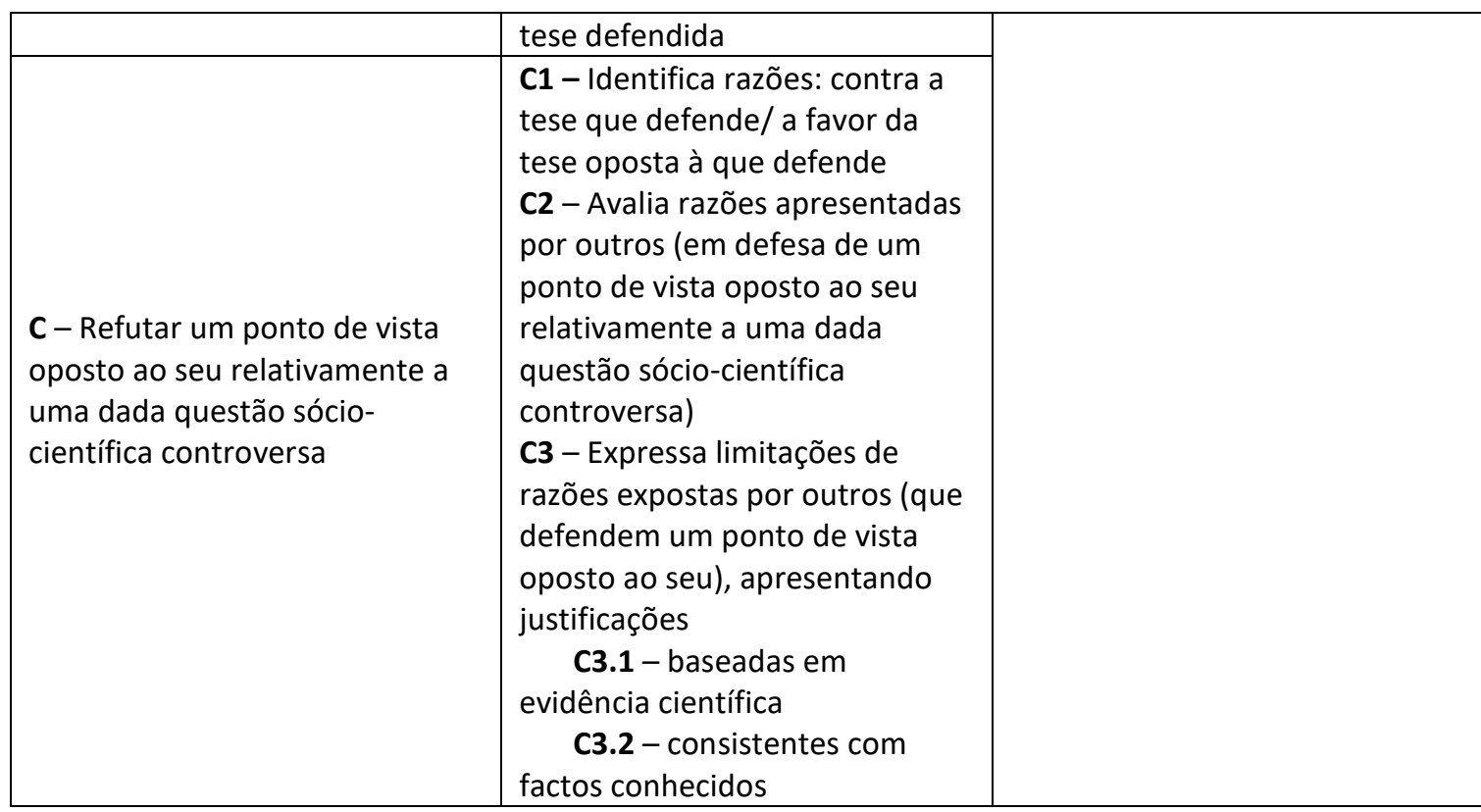

Quadro 1 - Capacidades de argumentação a promover na abordagem de questões sócio-científicas controversas

O referido Quadro 1 evidencia as capacidades de pensamento envolvidas na argumentação, às quais se procurou apelar nas situações de aprendizagem construídas tendo por base diferentes questões sócio-científicas controversas, formuladas no contexto de temas do programa de ciências dos alunos envolvidos no estudo. De clarificar a inclusão, neste referencial, de capacidades de argumentação como capacidades transversais, decorrente do facto de o seu uso, por norma, ser concomitante com o uso de outras capacidades de argumentação.

Estabelecido o referencial a usar relativamente à argumentação, analisou-se o programa curricular de ciências a fim de selecionar os tópicos favoráveis ao desenvolvimento de situações enquadradoras de cada questão sócio-científica controversa a ser abordada em sala de aula. Selecionados os tópicos, delinearam-se as situações ou contextos de partida e formularam-se as questões sócio-científicas controversas, definindo-se uma estratégia a usar na abordagem das mesmas em sala de aula. O Quadro 2 apresenta o tópico curricular subjacente à situação criada e respetiva questão sócio-científica formulada, bem como a estratégia usada na abordagem da mesma em sala de aula. 


\begin{tabular}{|l|l|l|l|}
\hline Tópico curricular & \multicolumn{1}{|c|}{$\begin{array}{c}\text { Situação sócio- científica } \\
\text { controversa }\end{array}$} & \multicolumn{1}{c|}{$\begin{array}{c}\text { Questão sócio- científica } \\
\text { controversa }\end{array}$} & \multicolumn{1}{|c|}{ Estratégia } \\
\hline $\begin{array}{l}\text { Meios de } \\
\text { comunicação: } \\
\text { poluição atmosférica }\end{array}$ & $\begin{array}{l}\text { Taxação da entrada de } \\
\text { veículos, no centro da } \\
\text { cidade de Lisboa, por causa } \\
\text { da poluição atmosférica }\end{array}$ & $\begin{array}{l}\text { Concordas com a medida? } \\
\text { Porquê? }\end{array}$ & $\begin{array}{l}\text { Ensaio } \\
\text { argumentativo }\end{array}$ \\
\hline $\begin{array}{l}\text { Aspetos físicos do } \\
\text { meio local: poluição } \\
\text { ambiental }\end{array}$ & $\begin{array}{l}\text { Poluição da Ribeira dos } \\
\text { Milagres causada por } \\
\text { suiniculturas existentes nas } \\
\text { proximidades }\end{array}$ & $\begin{array}{l}\text { Se fosses morador da } \\
\text { localidade onde se } \\
\text { encontram estas } \\
\text { suiniculturas, eras a favor ou } \\
\text { contra o seu encerramento? }\end{array}$ & Debate \\
\hline $\begin{array}{l}\text { A agricultura do } \\
\text { Meio local: uso de } \\
\text { pesticidas }\end{array}$ & $\begin{array}{l}\text { Interposição junto do } \\
\text { ministério público, por parte } \\
\text { de um grupo ambientalistas, } \\
\text { de um pedido de proibição } \\
\text { de utilização de pesticidas, } \\
\text { pelos agricultores, na } \\
\text { plantação de milho. }\end{array}$ & $\begin{array}{l}\text { Que decisão deve tomar o } \\
\text { Ministério Público? }\end{array}$ & $\begin{array}{l}\text { Desempenho de } \\
\text { papéis }\end{array}$ \\
\hline $\begin{array}{l}\text { A exploração mineral } \\
\text { do meio local: } \\
\text { efeitos nos } \\
\text { ecossistemas }\end{array}$ & $\begin{array}{l}\text { Exploração de uma pedreira } \\
\text { próxima de uma localidade }\end{array}$ & $\begin{array}{l}\text { Se fosses morador daquela } \\
\text { vila eras a favor ou contra o } \\
\text { encerramento da pedreira? }\end{array}$ & Debate \\
\hline $\begin{array}{l}\text { Os seres vivos do } \\
\text { ambiente próximo }\end{array}$ & $\begin{array}{l}\text { Utilização de animais na } \\
\text { investigação médica }\end{array}$ & $\begin{array}{l}\text { Deve ser permitido o uso de } \\
\text { animais na investigação } \\
\text { médica? }\end{array}$ & $\begin{array}{l}\text { Ensaio } \\
\text { argumentativo }\end{array}$ \\
\hline
\end{tabular}

Quadro 2 - Tópico curricular, situação e questão sócio-científica controversa formulada e respetiva estratégia de abordagem em sala de aula

Com o propósito de potenciar o envolvimento dos alunos nas situações de aprendizagem desenvolvidas, perspetivou-se a organização da aula ou sessão em quatro momentos-base para a realização do trabalho do aluno: a) trabalho prévio, com base num guião fornecido para o efeito; b) apresentação e clarificação da situação e da questão sócio-científica controversa; c) desenvolvimento, sendo que este, em alguns casos, envolveu a preparação para o debate e a realização do debate; em outro a preparação para o desempenho de papéis e o desempenho dos mesmos em outros casos ainda envolveu a preparação e a escrita do ensaio argumentativo); e d) sistematização, nos casos em que as estratégias usadas foram o debate ou o desempenho de papéis. Clarifique-se que, nesse momento, os alunos foram solicitados a tomar novamente posição face à questão sócio-científica controversa em foco. Optou-se por essa estratégia para possibilitar aos alunos o explicitar de uma posição (a 
defendida inicialmente ou a oposta), integrando elementos que tivessem surgido no debate ou no desempenho de papéis.

Em apoio ao trabalho do aluno, no âmbito de cada situação de aprendizagem focada numa questão sócio-científica controversa, foi desenvolvido e entregue a cada aluno um guião (Guião do Aluno), o qual apresentava a situação e a questão problema e, a propósito desta, explicita as solicitações a que o aluno devia dar resposta. A título ilustrativo, no momento relativo ao trabalho prévio, os alunos foram solicitados a pesquisar informação em fontes diversificada (entre as quais documentos fornecidos para o efeito) para procurar razões a favor e contra um dado ponto de vista passível de ser defendido no contexto da questão sócio-científica controversa em causa, e a avaliar a credibilidade das fontes consultadas. Para a preparação do debate, por exemplo, os alunos foram solicitados a dar resposta às seguintes solicitações com respeito à questão sócio-científica subjacente ao mesmo: (i) Opinião defendida e (ii) Razões que apoiam a opinião defendida.

A implementação em sala de aula das situações desenvolvidas ocorreu, de fevereiro a junho, numa turma de 3 o ano de escolaridade, constituída por 25 alunos (13 meninas e 12 meninos) com idades compreendidas entre os oito e os nove anos.

No decurso da implementação foram recolhidos dados com base num instrumento de análise das produções dos alunos, desenvolvido para o efeito. 0 instrumento foi aplicado às produções escritas dos alunos relativas às respostas dadas no Guião do Aluno a cada solicitação integrada no mesmo, bem como às produções orais, conforme transcrição das audiogravações de cada aula.

$\mathrm{Na}$ construção desse instrumento consideraram-se duas categorias de análise: capacidades de argumentação e conhecimentos, em estrita relação com o foco de cada questão de investigação formulada. Como indicadores foram registadas as capacidades de argumentação e capacidades transversais à argumentação, bem como os conhecimentos que a serem construídos/mobilizados pelos alunos no contexto de cada situação de aprendizagem focada na abordagem de uma questão sócio-científica controversa. Para tal, e de forma a haver coerência interna no estudo, o instrumento foi elaborado com base no referencial relativo às capacidades de argumentação usado no desenvolvimento das situações de aprendizagem. No que reporta à segunda categoria, os conhecimentos científicos a serem construídos/mobilizados foram 
identificados tendo como referência os enunciados no programa curricular para cada tópico subjacente às questões sócio-científicas abordadas.

\section{$4 \quad$ Resultados}

As questões orientadoras deste estudo prendem-se com os contributos da abordagem de questões sócio-científicas na promoção de capacidades de argumentação e na construção/mobilização de conhecimentos científicos. Em resposta a tais questões, apresentam-se, de seguida, os resultados obtidos, decorrentes da análise das produções dos alunos, escritas e orais, dos alunos, usando o instrumento desenvolvido para tal.

\subsection{Capacidades de argumentação}

A Tabela 1 apresenta os resultados relativos ao número de alunos, e a respetiva percentagem, que evidenciou a mobilização de capacidades de argumentação a que apelava em cada questão do guião do aluno relativo à abordagem de cada questão sócio-científica controversa. Note-se que nem todos os alunos da turma estiveram presentes em todas as sessões (aulas) realizadas, por isso entre parêntesis é indicado o número de alunos que respondeu a cada questão solicitada no Guião do aluno referente a cada sessão. 
Tabela 1 - Número e percentagem de alunos que evidenciou capacidades de argumentação, em cada questão do guião do aluno, por sessão

\begin{tabular}{|c|c|c|c|c|c|c|c|c|c|}
\hline \multirow{4}{*}{ 窇 } & \multirow{4}{*}{$\begin{array}{l}\text { Questão } \\
\text { (Guião } \\
\text { alunos) }\end{array}$} & \multicolumn{8}{|c|}{ Capacidades de argumentação } \\
\hline & & \multicolumn{4}{|c|}{ B } & \multicolumn{4}{|c|}{ C } \\
\hline & & \multirow{2}{*}{ B1 } & \multicolumn{3}{|c|}{ B2 } & \multirow{2}{*}{ C1 } & \multirow{2}{*}{ C2 } & \multicolumn{2}{|c|}{ C3 } \\
\hline & & & B2.1 & B2.2 & B2.3 & & & C3.1 & C3.2 \\
\hline 1 & Q1 (n=23) & $\begin{array}{c}17 \\
(74 \%)\end{array}$ & --- & $\begin{array}{c}13 \\
(57 \%)\end{array}$ & $\begin{array}{c}13 \\
(57 \%)\end{array}$ & & & & \\
\hline \multirow[b]{2}{*}{2} & Q1 $(n=23)$ & $\begin{array}{c}21 \\
(91 \%)\end{array}$ & $\begin{array}{c}2 \\
(9 \%) \\
\end{array}$ & $\begin{array}{c}13 \\
(57 \%)\end{array}$ & $\begin{array}{c}13 \\
(57 \%)\end{array}$ & & & & \\
\hline & Q3 (n=23) & $\begin{array}{c}23 \\
(100 \%)\end{array}$ & $\begin{array}{c}4 \\
(17 \%)\end{array}$ & $\begin{array}{c}22 \\
(96 \%)\end{array}$ & $\begin{array}{c}22 \\
(96 \%)\end{array}$ & & & & \\
\hline \multirow{2}{*}{3} & $\begin{array}{l}\text { Q1- grupo } \\
(n=22)\end{array}$ & $\begin{array}{ll}-- \\
\end{array}$ & $\begin{array}{c}4 \\
(100 \%)\end{array}$ & $\begin{array}{c}4 \\
(100 \%)\end{array}$ & $\begin{array}{c}4 \\
(100 \%)\end{array}$ & & & & \\
\hline & Q3 $(n=22)$ & --- & $\begin{array}{c}\mathbf{5} \\
(23 \%) \\
\end{array}$ & $\begin{array}{c}15 \\
(68 \%)\end{array}$ & $\begin{array}{c}18 \\
(82 \%) \\
\end{array}$ & & & & \\
\hline \multirow{2}{*}{4} & Q1 $(n=22)$ & $\begin{array}{c}21 \\
(95 \%)\end{array}$ & $\begin{array}{c}2 \\
(9 \%)\end{array}$ & $\begin{array}{c}19 \\
(86 \%)\end{array}$ & $\begin{array}{c}20 \\
(91 \%)\end{array}$ & & & & \\
\hline & Q3 (n=22) & $\begin{array}{c}22 \\
(100 \%)\end{array}$ & $\begin{array}{c}2 \\
(9 \%)\end{array}$ & $\begin{array}{c}19 \\
(86 \%)\end{array}$ & $\begin{array}{c}19 \\
(86 \%)\end{array}$ & & & & \\
\hline \multirow{4}{*}{5} & Q1 $(n=23)$ & $\begin{array}{c}23 \\
(100 \%)\end{array}$ & & & & & & & \\
\hline & Q2 (n=23) & & $\begin{array}{c}1 \\
(4 \%)\end{array}$ & $\begin{array}{c}21 \\
(91 \%)\end{array}$ & $\begin{array}{c}21 \\
(91 \%)\end{array}$ & & & & \\
\hline & Q3 $(n=23)$ & & & & & $\begin{array}{c}22 \\
(96 \%)\end{array}$ & & & \\
\hline & Q4 (n=23) & & & & & & $\begin{array}{c}\mathbf{1 7} \\
(\mathbf{7 4 \%})\end{array}$ & $\begin{array}{c}1 \\
(4 \%)\end{array}$ & $\begin{array}{c}17 \\
(74 \%)\end{array}$ \\
\hline
\end{tabular}

Da leitura do quadro, constata-se que, no decurso das sessões, houve um aumento do número de alunos que evidenciou ter mobilizado a capacidade de tomar uma posição quando confrontado com uma questão sócio-científica controversa, explicitando a tese que defende (capacidade B1). Relativamente à apresentação de razões para justificar a tese (B2), excetuando a questão 3 da situação de aprendizagem 2, denota-se um ligeiro aumento do número de alunos a mobilizar essa capacidade ao longo das sessões, especialmente na consistência das razões apresentadas com a tese defendida e com factos conhecidos (B2.3 e B2.2, respetivamente).

A título ilustrativo, inclui-se um exemplo das produções escritas dos alunos no âmbito da mobilização da capacidade explicitar e defender uma posição a propósito de uma questão sócio-científica controversa. O exemplo reporta à resposta de uma aluna à questão - Desempenha o papel dos Ambientalistas que entregaram a providência cautelar ao Ministério Público e redige um texto, para o convencer a impedir a 
utilização de pesticida, na plantação de milho, por parte dos Agricultores - efetuada após o desempenho de papéis, do guião do aluno, na 3ํㅗ sessão:

\footnotetext{
Eu a ambientalista Cláudia (nome fictício) vim defender o meio ambiente. Senhor do Ministério Público já sabe que muitas pessoas morrem por causa da utilização de pesticidas?

Muitos pesticidas afetam os solos e as águas. As águas que bebemos podem estar afetadas e assim ainda mais pessoas morrem.

Os pesticidas são perigosos, porque muitas pessoas morrem por causa de intoxicações.

Isto é uma injustiça para o meio ambiente!

Os animais também podem falecer pois bebem as águas e as plantas que pelas raízes os alimentos morrem.

Um por todos e todos pelo ambiente!
}

A resposta transcrita evidencia que a aluna apresenta razões consistentes com a tese que defende (contra a utilização de pesticidas na plantação) e baseadas em evidência científica, porquanto refere: os pesticidas são perigosos, porque muitas pessoas morrem por causa de intoxicações. O excerto sugere, ainda, que a aluna se baseou em informação de cariz científico, presente no texto facultado para a realização do trabalho prévio, para construir a razão apresentada em suporte da tese defendida.

A resposta da aluna ressalta, ainda, a mobilização de capacidades transversais à argumentação, designadamente, o ter presente a audiência e a persuasão, patente na forma como a aluna procura convencer/persuadir a audiência da consistência da posição que defende; e o uso de linguagem adequada à situação, incluindo linguagem científica, evidente, por exemplo, no enunciado: os pesticidas são perigosos, porque muitas pessoas morrem por causa de intoxicações.

Para além da mobilização de capacidades de argumentação, na resposta da aluna, denota-se a mobilização de conhecimentos, por exemplo, quando refere: [...]as plantas que pelas raízes sugam os alimentos [...]; no entanto, ao fazê-lo, ao afirmar que as plantas sugam alimentos pelas raízes, revela uma ideia discordante com o conhecimento científico atualmente aceite.

Focando a atenção na capacidade de argumentação Refutar um ponto de vista oposto ao seu relativamente a uma dada questão sócio-científica controversa (capacidade C), os resultados obtidos, conforme mostra a Tabela 1, indicam que os alunos mobilizaram a capacidade referida. 
Essa mobilização constatou-se nas produções orais dos alunos, ocorridas durante a realização dos debates e do desempenho de papéis (sessões 2, 4 e 3, respetivamente). Exemplo disso é o seguinte episódio, ocorrido na 2a sessão:

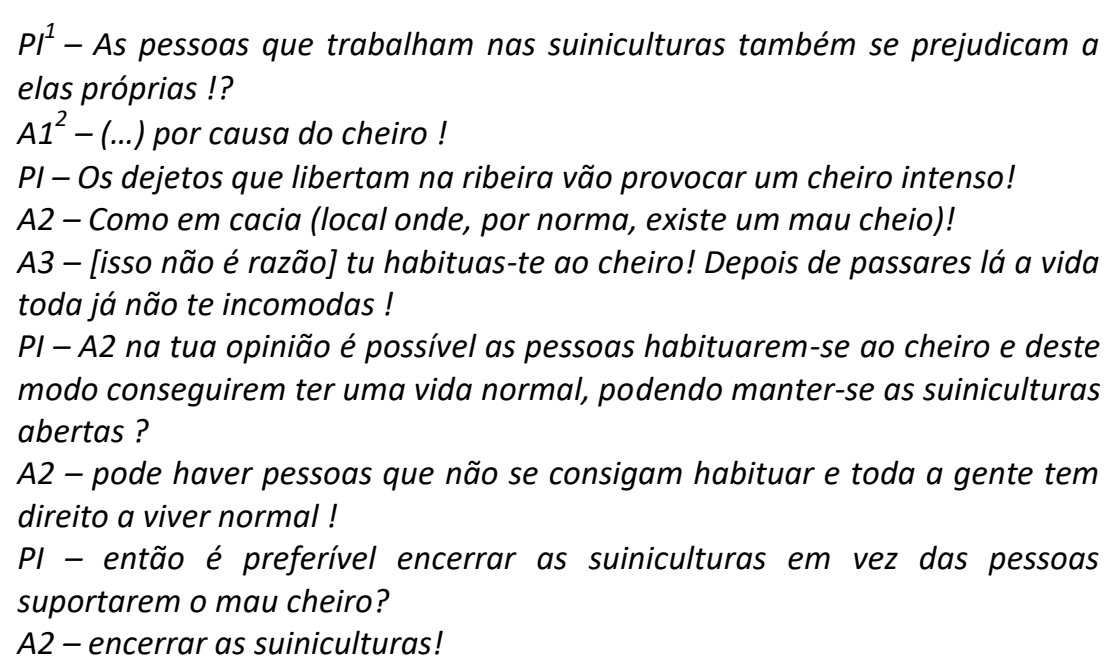

Como se pode constatar, o aluno A3 procurou refutar a razão apontada por A1, para o encerramento das suiniculturas, expressando pouca valoração da mesma, ao considerar que as pessoas que vivem próximas das suiniculturas são capazes de se habituar ao mau cheiro; assim sendo, para o aluno (A3) a razão apresentada pelo colega (A1) não se afigura suficientemente forte para se encerrar as suiniculturas. Por sua vez, A2 refuta o ponto de vista apresentado por A3, referindo que: pode haver pessoas que não se consigam habituar [...], expressando, desse modo, limitações da razão apontada por $A 3$, e, por conseguinte, o sublinhar do assumir uma posição favorável ao encerramento das suiniculturas.

Na 5ạ sessão, a mobilização da capacidade supramencionada também se constatou quando os alunos: (i) Identificaram razões a favor da tese oposta à que defende: Pode trazer sofrimento aos animais; (ii) São capazes de avaliar razões expressas por outros (em defesa do ponto de vista oposto ao seu relativamente à questão sócio-científica controversa), como patente na fala: mas mais vale morrerem os animais do que nós; e (iii) São capazes de expressar limitações de razões expostas por outros, apresentando justificações consistentes com factos conhecidos, conforme ilustra a transcrição: prefiro que os animais sofram com as investigações do que o ser humano.

\footnotetext{
${ }^{1}$ Professor

${ }^{2}$ Aluno 1
} 
Em relação à mobilização da capacidade analisar fontes de informação credíveis e relevantes em função de uma dada questão sócio-científica controversa, esta verificou-se na realização do trabalho prévio solicitado aos alunos nas sessões 3, 4 e 5. Por exemplo, na sessão 4 , verifica-se que $77 \%$ dos alunos evidenciaram a capacidade de analisar fontes de informação credíveis e relevantes em função da questão sóciocientífica controversa. A ilustrá-lo, transcreve-se um excerto corresponde à produção de um aluno em resposta à questão 1 (Se fosses morador daquela vila eras a favor ou contra o encerramento da pedreira?) do guião do aluno:

Eu sou a favor e apresento que "nos últimos anos tem-se verificado um aumento do número de pessoas, principalmente trabalhadores da pedreira, afetadas com doenças respiratórias.

No contexto da 5a sessão também foi solicitado aos alunos a realização de um trabalho prévio (primeiro momento em que se organizou cada sessão) que consistia no pesquisar, em diferentes fontes de informação, incluindo os documentos fornecidos pelo professor, razões a favor e contra o uso de animais na investigação médica. Através da realização desse trabalho pôde constatar-se que todos os alunos identificaram razões a favor e contra o uso de animais na investigação médica. Refirase que $74 \%$ dos alunos analisaram pelo menos três fontes de informação, $9 \%$ duas fontes de informação e $17 \%$ apenas o texto fornecido. Esses resultados evidenciam um ligeiro aumento do número de fontes de informação credíveis e relevantes analisadas pelos alunos em função da questão sócio-científica controversa abordada nessa sessão, comparativamente com os resultados obtidos no contexto da sessão 3 (59\% dos alunos analisaram pelo menos três fontes de informação, 32\% consultaram duas fontes de informação e $9 \%$ usaram apenas como fonte de informação os documentos fornecidos pelo professor).

Quanto à validade e consistência com factos conhecidos, das razões expostas em relação aos dois pontos de vista distintos (a favor ou contra a utilização de pesticidas na agricultura), verificou-se que a maioria das razões apresentadas era consistente com o respetivo ponto de vista. 


\subsection{Conhecimentos construídos/mobilizados}

Apresenta-se, de seguida, a Tabela 2, que traz os resultados obtidos, decorrentes da análise das produções escritas e orais dos alunos, focada no identificar evidências da construção/mobilização de conhecimento científico em foco em cada sessão, em função da questão sócio-científica controversa abordada. De referir que nas sessões 3 e 4 dos 23 alunos da turma, apenas estiveram presentes 22 alunos, pois um faltou.

Tabela 2 -Número e percentagem de alunos que evidenciou construção/mobilização de conhecimento científico em foco em cada sessão

\begin{tabular}{|c|c|c|}
\hline Sessão & Conhecimentos Científicos em foco & $\begin{array}{l}\text { № e percentagem de } \\
\text { alunos que evidenciam } \\
\text { a sua mobilização }\end{array}$ \\
\hline \multirow{2}{*}{1} & $\begin{array}{l}\text { Refere meios de transporte terrestres que são (i) exemplos e (ii) } \\
\text { não exemplos de fontes de poluição da atmosfera }\end{array}$ & $5(27 \%)$ \\
\hline & $\begin{array}{l}\text { Identifica consequências (positivas e/ou negativas) da utilização de } \\
\text { meios de transporte terrestres }\end{array}$ & $12(52 \%)$ \\
\hline \multirow[t]{2}{*}{2} & $\begin{array}{l}\text { Identifica consequências } \\
\text { (positivas e/ou negativas) causadas pela criação de gado }\end{array}$ & $23(100 \%)$ \\
\hline & Reconhece a criação de gado como uma atividade económica & $11(48 \%)$ \\
\hline \multirow{3}{*}{3} & $\begin{array}{l}\text { Identifica efeitos (positivos e/ou negativos) causados pela } \\
\text { utilização de pesticidas }\end{array}$ & $20(91 \%)$ \\
\hline & Reconhece a agricultura como uma atividade económica & $14(64 \%)$ \\
\hline & Reconhece fatores que afetam a produtividade dos solos & $4(18 \%)$ \\
\hline \multirow{3}{*}{4} & $\begin{array}{l}\text { Identifica consequências (positivas e/ou negativas) decorrentes da } \\
\text { exploração mineira }\end{array}$ & $20(91 \%)$ \\
\hline & Reconhece a exploração mineira como uma atividade económica & $19(86 \%)$ \\
\hline & $\begin{array}{l}\text { Reconhece a exploração mineira como uma fonte de matérias- } \\
\text { primas }\end{array}$ & $6(27 \%)$ \\
\hline \multirow[t]{2}{*}{5} & $\begin{array}{l}\text { Identifica consequências (positivas e/ou negativas) da utilização de } \\
\text { animais na investigação médica. }\end{array}$ & $23(100 \%)$ \\
\hline & Nomeia animais comummente usados na investigação médica & $5(27 \%)$ \\
\hline
\end{tabular}

Conforme se pode verificar através da leitura do quadro, diversos alunos evidenciaram a construção/mobilização de conhecimentos em foco, relativos a cada sessão realizada. A título ilustrativo, na 3ạ sessão, dos conhecimentos em foco destacase o identificar efeitos (positivos e/ou negativos) causados pela utilização de pesticidas, sendo que $91 \%$ dos alunos evidenciou tê-lo mobilizado. Tal, constata-se, por exemplo, na seguinte resposta:

Os pesticidas podem provocar doenças em qualquer pessoa.

Se um menino foi apanhar água a um rio essa água pode estar infetada. 
No ar também pode haver pesticidas e se alguma pessoa passar por lá pode apanhar alguma doença.

$\mathrm{Na}$ resposta do aluno, assinala-se a mobilização de conhecimento científico, nomeadamente, a última frase que nos indica conceções do aluno ao referir consequências negativas para o ser humano, decorrente da utilização de pesticidas na agricultura.

No que concerne ao reconhecer a agricultura como uma atividade económica, 64\% dos alunos evidenciaram a construção/mobilização desse conhecimento, tal como se pode observar no seguinte exemplo da resposta de um aluno à questão 3 do guião do aluno: Isso [utilização de pesticidas] também aumentou a produção de alimento, diminuiu o desemprego, ajudou o crescimento económico.

Nessa resposta nota-se que o aluno reconhece a agricultura como uma atividade económica, na medida em que se refere à produção de alimento no sentido de o comercializar. O aluno referiu, ainda, a diminuição do desemprego e o crescimento económico.

\section{$5 \quad$ Considerações Finais}

A partir dos resultados da presente investigação pode dizer-se que a abordagem de questões sócio-científicas controversas contribuiu para o desenvolvimento da capacidade de argumentação dos alunos, especificamente: analisar fontes de informação credíveis e relevantes, tomar uma posição e defendê-la e refutar um ponto de vista oposto ao seu, acerca de uma questão sócio-científica controversa. No que concerne à construção/mobilização de conhecimentos científicos, os resultados obtidos apontam no sentido de que a abordagem de questões sóciocientíficas controversas levou os alunos a construírem e mobilizarem conhecimento científico.

Nesse quadro, o estudo realizado configura-se como um contributo para o desenvolvimento de práticas de educação em ciências, visando a formação de cidadãos capazes de pensar e de se envolver na discussão e resolução de questões pessoal e socialmente relevantes, com uma componente científico-tecnológica. Portanto, os documentos, materiais e instrumentos concebidos afiguram-se como uma 
ajuda para os professores, em particular, os professores do 1 을 CEB integrarem nas suas práticas de ensino das ciências a abordagem de questões sócio-científicas controversas, orientadas para o promover capacidades de argumentação dos alunos, em conjugação com a construção/mobilização de conhecimento científico.

\section{Referências}

BOCANERA, C.; SILVA, L. (2009). Planejamento e Execução de Atividades de Ensino a Partir de Temas Controversos: Relato de uma Experiência Interdisciplinar. Disponível em: $\quad$ http://www.sbf1.sbfisica.org.br/eventos/snef/xviii/sys/resumos/T0403-1.pdf. Acedido em: 1 jan. 2012.

BRITO, J.; SÁ, L. Estratégias promotoras da Argumentação sobre Questões Sóciocientíficas com alunos de Ensino Médio. Revista Electrónica de Enseñanza de las Ciencias, Vigo, v. 9, n. 3, p. 505-52. 2010. Disponível em: http://www.saum.uvigo.es/REEC/volumenes/volumen9/ART2_Vol9_N3.pdf. Acedido em: 1 jan. 2012.

CAPECCHI, M.; CARVALHO, A. Argumentação em uma aula de conhecimento físico na faixa de oito a dez anos. Investigações em Ensino de Ciências, Porto Alegre, v.5, n.3, p. 171-189, Set. 2000.2 Disponível em: http://www.if.ufrgs.br/public/ienci/artigos/Artigo_ID63/v5_n3_a2000.pdf. Acedido em: 4 jan. 2012.

CID, M.; MEMBIELA, P.; NOGUEIRAS, E.; VIDAL, M. (2004). Experiencias de integración del enfoque CTS en la formación de los maestros. In: MARTINS, I. P.; PAIXÃO, F.; VIEIRA, R. M. (Orgs.). Perspectivas Ciência-Tecnologia-Sociedade na Inovação da Educação em Ciência. Aveiro: Universidade de Aveiro, 2004. p. 57-62.

COSTA, A. Desenvolver a capacidade de argumentação dos estudantes: um objetivo pedagógico fundamental. Revista Iberoamericana de Educación, v.46, n. 5, p.1-8, Jun. 2008. Disponível em: http://www.rieoei.org/deloslectores/2233Costa.pdf. Acedido em: 6 jan. 2012.

DRIVER, R.; NEWTON, P.; OSBORNE, J. Establishing the norms of scientific argumentation in classrooms. Science Education, v.84, n.3, p. 287-312, Mai. 2000. Disponível em: http://cset.stanford.edu/sites/default/files/files/documents/publications/Osborne- 
Establishing\%20the\%20Norms\%20of\%20Scientific\%20Argumentation.pdf. Acedido em: 2 jan. 2012.

ENNIS, R. Critical thinking. Upper Saddle River. New Jersey: Prentice Hall, 1996.

HILÁRIO, T.; REIS, P. Potencialidades e Limitações de Sessões de Discussão de Controvérsias Sociocientíficas como Contributos para a Literacia Científica. REU, Sorocaba, São Paulo, v.35, n.2, p. 167-183, Dez. 2009. Disponível em: http://repositorio.ul.pt/bitstream/10451/4617/1/Discussao-de-controversiassociocientificas-contributos-para-a-literacia-cientifica.pdf. Acedido em: 1 jan. 2012.

HILÁRIO, T.; REIS, P. Potencialidades e limitações da discussão de controvérsias sociocientíficas através da representação de papéis: um estudo de caso. Nuances: Estudos sobre Educação, São Paulo, v.19, n.20, p.86-95, Mai./Ago. 2011. Disponível em: http://revista.fct.unesp.br/index.php/Nuances/article/viewFile/982/983. Acedido em: 4 jan. 2012.

HAKYOLU, H.; OGAN-BEKIROGLU, F. Assessment of Students' Science Knowledge Levels and Their Involvement with Argumentation. International Journal for CrossDisciplinary Subjects in Education, v.2, n.1, p. 264-270, Mar. 2011.

JIMÉNEZ-ALEIXANDRE, P.; ERDURAN, S. Argumentation in science education: An overview. In: S. Erduran; P. Jiménez-Aleixandre (Eds.). Argumentation in science S-TEAM Deliverable 7b: Report on Argumentation and Teacher Education in Europe education: perspectives from classroom-based research. Dordrecht: Springer, 2008. p.3-27.

LEITÃO, S. Argumentação e Desenvolvimento do Pensamento Reflexivo. Psicologia: Reflexão e Crítica, Porto Alegre, v.20, n.3, p.454-462, 2007. Disponível em: http://www.scielo.br/pdf/prc/v20n3/a13v20n3.pdf. Acedido em: 4 jan. 2012.

MARTINS, I. (2011). Ciência e Cidadania: perspetivas de Educação em Ciência. In LEITE L.; AFONSO, A. S.; DOURADO L.; VILAÇA, T.; MORGADO, S.; ALMEIDA S. (Orgs.). Actas do XIV Encontro Nacional da Educação em Ciências. Braga: Universidade do Minho, 2011. p. 21-31.

MORTIMER, E. F.; SCOTT, P. Atividade Discursiva nas Salas de Aulas de Ciências: Uma Ferramenta Sociocultural para Analisar e Planejar o Ensino. Investigação em Ensino de ciências, Porto Alegre - RS, v.7, n. 3, p. 01-24, Set. 2002. Disponível em: 
<http://www.if.ufrgs.br/public/ensino/vol7/n3/v7-n3-a7.htm>. Acedido em: 12 jul 2004.

NORRIS, S.; PHILLIPS, L.; OSBORNEs, J. (2007). Scientific Inquiry: The Place of Interpretation and Argumentation. Science as inquiry in the secondary setting, p. 8798. Disponível em: http://iss.rbe.sk.ca/files/Ch8InterpretationandArgumentation.pdf. Acedido em: 2 jan. 2012.

OSBORNE, J. Science education for the twenty first century. Eurasia Journal of Mathematics, Science \& Technology Education, v.3, n.3, p.173-184, Ago. 2007. Disponível em: http://www.ejmste.com/v3n3/EJMSTE_v3n3_Osborne.pdf. Acedido em: 4 jan. 2012.

PEREIRA, D. Nova Educação na nova Ciência para a nova Sociedade. Porto: Editora da Universidade do Porto, 2007.

REIS, P. Controvérsias Sócio-Científicas: discutir ou não discutir? Lisboa: Faculdade de Ciências da Universidade de Lisboa, 2004.

REIS, P. Ciência e Controvérsia. REU, Sorocaba, São Paulo, v.35, n.2, p.09-15, Dez. 2009. Disponível em: http://repositorio.ul.pt/bitstream/10451/4615/1/Ciencia-econtroversia.pdf. Acedido em: 1 jan. 2012.

STIEFEL, B. et al. (2004). Impacte de um Programa de Formação com uma Orientação CTS/PC nas Concepções e Práticas de Professores. In: MARTINS, I. P.; PAIXÃO, F.; VIEIRA, R. M. (Orgs.). Perspectivas Ciência-Tecnologia-Sociedade na Inovação da Educação em Ciência. Aveiro: Universidade de Aveiro, 2004. p. 89-97.

TENREIRO-VIEIRA, C.; VIEIRA, R. Produção e validação de materiais didácticos de cariz CTS para a educação em ciências no ensino básico. In: MARTINS, I. P.; PAIXÃO, F.; VIEIRA, R. M. (Orgs.). Perspectivas Ciência-Tecnologia-Sociedade na Inovação da Educação em Ciência. Aveiro: Universidade de Aveiro, 2004. p. 81-87.

VIEIRA, R.; TENREIRO-VIEIRA, C.; MARTINS, I. A educação em ciências com orientação CTS: atividades para o ensino básico. Porto: Areal Editores, 2011. 
ZOHAR, A.; NEMET, F. Fostering Students' Knowledge and Argumentation Skills Through Dilemmas in Human Genetics. Journal of Research in Science Teaching, v.39, n.1, p.35-62, Jan. 2002.

Enviado em Julho/2014 Aprovado em Novembro/2014 